\title{
Editorials
}

\section{Managing the consequences of cancer in primary care}

Progress in the early detection and treatment of many types of cancer, coupled with an ageing population, has meant that the numbers of people living with cancer are increasing. Across the UK there are around 2.5 million people living with or beyond a cancer diagnosis, projected to grow to $>4$ million by 2030. ${ }^{1}$ Half of those diagnosed with cancer today are predicted to survive for $\geq 10$ years, however survivors of cancer report poorer health and wellbeing than the general population., ${ }^{2,3}$

While cancer specialists do their best to minimise toxicities from treatment, it is inevitable that some healthy tissue is damaged. Whether this leads to long-term problems, such as those shown in Table 1, ${ }^{4}$ depends on a number of different factors including: treatment type, dosage and frequency; age; sex; lifestyle factors; and preexisting conditions. What we do know is that a significant minority of patients with cancer will experience persistent problems that negatively affect their quality of life.

People who have been treated for cancer are also at an increased risk of a second primary cancer and long-term conditions such as endocrine disorders, osteoporosis and heart disease. The risks are particularly high among those treated as children or young adults. ${ }^{5}$

There is growing awareness that more needs to be done to improve the quality of life of people who have had cancer and to reduce their risk of long-term health problems. Recent cancer care strategies in England and Scotland emphasise patient experience and recommend measures to support people living with and beyond cancer. Among these recommendations is a recovery package for cancer patients, including holistic assessment and care planning, a standardised treatment summary, and cancer care review. ${ }^{6}$

\section{IMPLICATIONS FOR PRIMARY CARE}

Routine hospital based follow-up models across all cancer types are no longer sustainable, and in many cases can be of limited benefit. Increasingly, a 'risk stratified approach is being adopted, where those at low risk of recurrence are supported to self-manage in the community. Studies have shown that patients and GPs are in favour of primary care having a greater role in cancer follow-up, including the diagnosis and management of physical and psychological

\section{Table 1. Estimated prevalence of common consequences of cancer treatment ${ }^{4}$}

\begin{tabular}{lc} 
Consequence of cancer treatment & Estimated UK prevalence \\
\hline Chronic fatigue & 350000 \\
\hline $\begin{array}{l}\text { Sexual difficulties } \\
\text { Including problems preventing a normal sex life, for example, erectile dysfunction; } \\
\text { penile shortening; vaginal dryness; stenosis and shortening; sexual pain and } \\
\text { loss of sexual interest; and psychosexual problems }\end{array}$ & 350000 \\
\hline $\begin{array}{l}\text { Mental health problems } \\
\text { Including moderate to severe anxiety or depression, and post-traumatic stress disorder }\end{array}$ & 240000 \\
\hline $\begin{array}{l}\text { Moderate to severe pain } \\
\text { Chronic changes in urinary function }\end{array}$ & 200000 \\
$\begin{array}{l}\text { Including incontinence, urgency, decreased capacity, frequency, nocturia, ulcer, } \\
\text { telangiectasia, haematuria, fistula }\end{array}$ & 150000 \\
\hline $\begin{array}{l}\text { Chronic changes in lower gastrointestinal function } \\
\text { Including diarrhoea, faecal incontinence, urgency, flatulence, bleeding, hernia, }\end{array}$ & 90000 \\
$\begin{array}{l}\text { adhesions, strictures, pain, fistula } \\
\text { Menopausal and hormonal symptoms }\end{array}$ & \\
$\begin{array}{l}\text { Including hot flushes and sleep disturbance lin men and women), vaginal dryness, } \\
\text { early menopause }\end{array}$ & 80000 \\
\hline $\begin{array}{l}\text { Chronic changes in upper gastrointestinal function } \\
\text { Including swallowing, voice dysfunction, tube feeding, trismus, nausea, weight loss }\end{array}$ & 50000 \\
\hline $\begin{array}{l}\text { Endocrine system disorders } \\
\text { Including complex hormone dysfunction, thyroid dysfunction, androgen deficiency, } \\
\text { metabolic syndrome, growth hormone deficiency, and primary ovarian failure. }\end{array}$ & Total could not \\
\hline & be estimated \\
\hline
\end{tabular}

effects of cancer and its treatment, yet both groups report concerns around GP expertise and engagement in this area. Key barriers to the provision of care include inadequate information from secondary care and a lack of knowledge around cancer side effects and follow-up requirements.

In recognition of the above, the Royal College of General Practitioners (RCGP) chose 'Consequences of Cancer' as one of its 2015-2016 'Spotlight' projects. Led by Macmillan Cancer Support, a leading UK cancer support charity, the project builds on work carried out by Macmillan and partners as part of the National Cancer Survivorship Initiative. The project aims to raise awareness and knowledge of the consequences of cancer treatment through the launch of a new online toolkit (www.rcgp.org.uk/coc) to help primary care professionals support patients following a cancer diagnosis, and a series of regional education events. The following steps, supported by the more detailed information and resources available in the toolkit, can help to address the needs of this growing patient population.

\section{AWARENESS OF POTENTIAL CONSEQUENCES}

Treatment summaries generated by secondary care are being used in some areas to provide details of the treatment received, prognosis and ongoing management plan, as well as highlighting potential consequences of treatment and any specific actions for the GP. Use of these summaries is still sporadic but as part of the recovery package roll-out there will be increased efforts to embed these within cancer care.

The possibility of consequences of treatment should be considered when patients with a history of cancer present with new symptoms. In those patients likely to develop cardiovascular disease or osteoporosis it is particularly important that a previous history of cancer is considered in the calculation of risk. However, a recent survey found that few GPs are aware of the associations between cancer treatment and reduced cardiovascular health and were unlikely to consider a previous history or cancer when doing an assessment. ${ }^{8}$

\section{IDENTIFYING PATIENTS AT RISK}

The consequences of cancer treatment may not become evident or start to impact on quality of life until several months or even 
years after treatment, and it is therefore necessary to remain vigilant and have systems in place to recognise those at risk. This is particularly important for people treated as children or young adults, who have a high risk of late-onset consequences. It is helpful to ensure that patient records are clearly coded with past oncological treatments and where possible, also coded as 'At increased risk of

It is also essential that significant events in the medical history are not lost with each new summarising of records.

Successful management of patients with cancer in primary care needs GPs to engage with such patients. The cancer care review at 6 months post-diagnosis is an opportunity to proactively ask about possible treatment-related problems and psychosocial effects, as patients may not feel confident to raise symptoms that they see as embarrassing or trivial. Trigger questions that are highly predictive of toxicity can help to identify patients that are in need of further assessment, for example, those patients who have had pelvic cancer treatment(Box 1). ${ }^{9}$

\section{SUPPORTING SELF MANAGEMENT}

Offering information on the signs and symptoms of cancer recurrence and consequences of treatment will help patients to know what to look out for and when to seek further support. It may be worth repeating or reinforcing this information at different stages, depending on the needs and preferences of the individual. Practical resources such as a toilet card (designed to give you urgent access to a toilet when out in public). ${ }^{10}$ or RADAR key (which can open locked facilities) for incontinence/urgency can help to improve quality of life while further investigations or treatment options are being explored.

The importance of physical activity and healthy lifestyle behaviours should not be underestimated. Being active during and after cancer treatment can help maintain physical function, improve psychological wellbeing and reduce the risk of recurrence and consequences of treatment in some cancer types. ${ }^{11}$ Many practice nurses have expertise in chronic condition management and are ideally positioned to play a key role in the follow-up of patients after a cancer diagnosis, particularly in assessment and self management support.

\section{MANAGING CONSEQUENCES OF TREATMENT IN PRIMARY CARE}

There are a huge range of potential consequences of cancer treatment, and people will have different needs depending on the type and severity of their symptoms.

\section{Box 1. Trigger questions}

The following questions should be asked regularly to patients who have had pelvic cancer treatment:

- Are you woken at night to have a bowel movement?

- Do you need to rush to the toilet to have a bowel movement?

- Do you ever have bowel leakage, soiling or a loss of control over your bowels?

- Do you have any bowel symptoms preventing you from living a full life?

For mild to moderate symptoms there are often simple and inexpensive interventions that can greatly improve patient outcomes. For example, dietary advice such as avoiding excessive fibre, pelvic floor exercises, and continence support are helpful for many GI problems, with referral to gastroenterology if symptoms do not improve. People with complex problems will benefit from specialist multidisciplinary care so the establishment of referral pathways is also important. The management of many late onset consequences differs little from management of other chronic conditions, the key is to be aware of the risks and monitor for problems appropriately. For people who received cardiotoxic therapies, regular cardiac surveillance is likely to be beneficial, while for those at risk of osteoporosis due to ongoing hormone therapy a DEXA scan may be required, in addition to dietary supplementation and bisphosphonates.

\section{CONCLUSION}

The role of primary care in cancer followup is still being defined but it is clear that managing the consequences of cancer and its treatment will be an increasing part of the GP workload. The RCGP Macmillan toolkit brings together existing best practice, clinical guidance, and patient resources, however further education, training, and resources are needed to increase knowledge and awareness of this under-recognised issue.

\section{David Linden,}

Macmillan GP Advisor and RCGP Consequences of Cancer Spotlight Project Clinical Lead, Macmillan Cancer Support, London.

\section{Pauline Love,}

Macmillan GP Advisor and RCGP Consequences of Cancer Spotlight Project Clinical Lead, Macmillan Cancer Support, London.

\section{Emily Bowman,}

Consequences of Treatment Project Manager, Macmillan Cancer Support, London.

\section{Jane Maher,}

Joint Chief Medical Officer, Macmillan Cancer Support, London.

\section{ADDRESS FOR CORRESPONDENCE}

\section{Jane Maher}

Macmillan Cancer Support, 89 Albert Embankment, London, SE1 7UQ, UK.

\section{E-mail: JMaheramacmillan.org.uk}

\section{Provenance}

Commissioned; externally peer reviewed.

\section{DOI: 10.3399/bjgp16X685789}

\section{REFERENCES}

1. Maddams J, Utley M, Møller H. Projections of cancer prevalence in the United Kingdom, 20102040. Br J Cancer 2012; 107: 1195-1202.

2. Cancer Research UK. Cancer survival statistics. http://www.cancerresearchuk.org/healthprofessional/cancer-statistics/survival\#headingZero laccessed 6 Jun 2016).

3. Elliott J, Fallows A, Staetsky L, et al. The health and well-being of cancer survivors in the UK: findings from a population-based survey. $\mathrm{Br} \mathrm{J}$ Cancer 2011, 105: S11-S20

4. Macmillan Cancer Support. Throwing light on the consequences of cancer and its treatment. 2013. http://uww.macmillan.org.uk/ Documents/AboutUs/Research/Researchand evaluationreports/Throwinglightonthe consequencesofcanceranditstreatment.pdf (accessed 6 Jun 2016).

5. Khan NF, Mant D, Carpenter L, et al. Long-term health outcomes in a British cohort of breast, colorectal and prostate cancer survivors: a database study. Br J Cancer 2011; 105: S29S37.

6. Independent Cancer Taskforce. Achieving world-class cancer outcomes: a strategy for England 2015-2020. 2015. http://www. cancerresearchuk.org/sites/default/files/ achieving_world-class_cancer_outcomes_-_a strategy_for_england_2015-2020.pdf laccessed 6 Jun 2016).

7. Meiklejohn JA, Mimery A, Martin JH, et al. The role of the GP in follow-up cancer care: a systematic literature review. J Cancer Surviv 2016, DOI 10.1007/s11764-016-0545-4.

8. Walter FM, Usher-Smith JA, Yadlapalli S, Watson E. Caring for people living with and beyond cancer: an online survey of GPs in England. Br J Gen Pract 2015; DOI: 10.3399/ bjgp15X687409.

9. Andreyev HJN, Davidson SE, Gillespie C, et al. Practice guidance on the management of acute and chronic gastrointestinal problems arising as a result of treatment for cancer. Gut 2012; 61(2): 179-192.

10. Macmillan Cancer Support. Macmillan Toilet Card. https://be.macmillan.org.uk/be/p-22493 generic-toilet-card.aspx laccessed 6 Jun 2016).

11. Macmillan Cancer Support. The importance of physical activity for people living with and beyond cancer: a concise evidence review. 2012. http:// unw.macmillan.org.uk/Documents/AboutUs/ Commissioners/Physicalactivityevidencereview. pdf (accessed 6 Jun 2016). 